Article

\title{
Fumarate Based Metal-Organic Framework: An Effective Catalyst for the Transesterification of Used Vegetable Oil
}

\author{
Mohammed Rafi Shaik*(D), Syed Farooq Adil *(D), Zeid A. ALOthman (1) and Osamah M. Alduhaish *(i) \\ Department of Chemistry, College of Science, King Saud University, P.O. Box 2455, Riyadh 11451, Saudi Arabia; \\ zaothman@ksu.edu.sa \\ * Correspondence: mrshaik@ksu.edu.sa (M.R.S.); sfadil@ksu.edu.sa (S.F.A.); oalduhaish@ksu.edu.sa (O.M.A.); \\ Tel.: +966-11-46-70439 (M.R.S.)
}

check for

updates

Citation: Shaik, M.R.; Adil, S.F.; ALOthman, Z.A.; Alduhaish, O.M. Fumarate Based Metal-Organic Framework: An Effective Catalyst for the Transesterification of Used Vegetable Oil. Crystals 2022, 12, 151. https://doi.org/10.3390/cryst12020151

Academic Editor: Marta E. G. Mosquera

Received: 29 December 2021

Accepted: 16 January 2022

Published: 21 January 2022

Publisher's Note: MDPI stays neutral with regard to jurisdictional claims in published maps and institutional affiliations.

Copyright: (C) 2022 by the authors. Licensee MDPI, Basel, Switzerland. This article is an open access article distributed under the terms and conditions of the Creative Commons Attribution (CC BY) license (https:// creativecommons.org/licenses/by/ $4.0 /)$.

\begin{abstract}
Advancement of technology for the sustainable production of biodiesel is of significant importance in fighting against rising fuel costs due to the fast depletion of fossil fuels. In this regard, the application of highly efficient MOFs (metal-organic frameworks)-based materials as acidic, basic, or supported heterogeneous catalysts plays a crucial role in enhancing the efficiency of biodiesel production processes. In this report, we demonstrate the synthesis and catalytic application of Zr-fumarate-MOF (also known as MOF-801) as a heterogeneous catalyst for the transesterification reaction of used vegetable oil (UVO) for the production of biodiesel. The formation of MOF-801 and its structural stability is confirmed by a variety of characterization techniques including XRD, SEM, EDX, FT-IR, BET, and TGA analyses. The results revealed the formations of highly crystalline, cubic MOF-801 possessing thermal stability below $500{ }^{\circ} \mathrm{C}$. The MOF- 801 catalyst demonstrated moderate catalytic activity during transesterification of UVO ( 60\%) at $50 \mathrm{wt} . \%$ of methanol: oil, $10 \mathrm{wt} . \%$ catalyst loading, $180{ }^{\circ} \mathrm{C}$ reaction temperature, and $8 \mathrm{~h}$ of reaction time. Furthermore, the catalyst has exhibited adequate reusability with a slight reduction in the reaction yield of up to $\sim 10 \%$ after three cycles.
\end{abstract}

Keywords: metal-organic framework; Zr-fumarate-MOF; catalyst; transesterification; vegetable oil

\section{Introduction}

Due to the fast depletion of oil reserves, the demand for alternative energy resources has increased tremendously [1]. Among various renewable energy resources, biofuels have found decent consideration and have been applied progressively as a suitable alternative to traditional fossil fuels [2]. Biofuels have greatly contributed in controlling the emission of greenhouse gases, which can cause a serious threat to the environment and human life [3,4]. Particularly, biofuels generated from renewable energy resources including plants and other naturally abundant materials have been appreciated due to their nontoxic and biodegradable nature [5]. For instance, biodiesel that is comprised of fatty acid methyl esters is typically obtained from various renewable resources, such as animal fats and vegetable oils, etc., have found several applications [6]. Biodiesel is generally obtained from the natural feedstock through the process of transesterification using suitable catalysts [7]. This type of fuel is less dangerous to the environment due to the low emission of greenhouse gases while burning including $\mathrm{SO}_{2}, \mathrm{SO}_{3}, \mathrm{CO}$, etc. In addition, biodiesel is more lubricious and easier to handle and contains lower amounts of carcinogenic substances when compared to the traditional fossil fuels [8,9].

Typically, transesterification of triglycerides present in used or edible oils is carried out in alcohols using acid or base catalysts to produce biodiesel. This process is usually performed under homogeneous conditions at mild temperatures using $\mathrm{KOH}, \mathrm{NaOH}$, etc., as catalysts [10]. However, acid catalysts such as $\mathrm{HCl}$ or $\mathrm{H}_{2} \mathrm{SO}_{4}$, etc., are more preferred for the triglycerides of used oils which effectively activate the substrates through the 
electrolytic process [11]. Particularly, for the triglycerides with low free fatty acid (FFA) contents, homogeneous basic catalysts deliver relatively more efficient catalytic activities when compared to the acid catalysts [12]. However, the applications of homogeneous catalysts are largely inhibited due to their high cost on separations and environmental hazards. Moreover, these types of catalysts also require long reaction times and suffer from saponification and corrosion problems [13].

Alternatively, heterogeneous catalysts are less expensive, more stable at high temperature and pressure, readily available, and easy to separate [14]. Therefore, these types of catalysts offer a suitable alternative to the conventional homogeneous catalysts for the production of biodiesel [15]. Indeed, there is a continued urge among researchers for the development of advanced heterogeneous catalysts for the sustainable production of biodiesel at a minimal cost [16]. To date, various studies have been published on the transesterification of glyceraldehydes using different types of heterogeneous catalysts during the production of biodiesel. However, the shortage of raw materials and high production costs still make the biodiesel more expensive when compared to conventional fossil fuels [17].

To overcome this problem, appropriate feedstock selection from renewable wastes, including non-edible crops, animal fats, used vegetable oils (UVO), etc., is highly desirable [18]. However, these types of renewable wastes often contain high free fatty acid (FFA) contents, which generally require a large amount of catalysts and higher purification costs $[19,20]$. Therefore, the conversion of cheap renewable wastes and non-edible fats into biodiesel products through simple economic and environmentally friendly processes using effective and low-cost heterogeneous catalysts is highly required [21]. Usually, the FFA contents are converted to their alkyl esters counterparts in the presence of different types of heterogeneous catalysts including acid, base, and bifunctional (acidic-basic character) catalysts [22]. Both solid acid and base catalysts have their own merits and demerits, such as the acid catalysts can effectively catalyze the esterification of FFAs even in the presence of large water and FFA contents [23].

Thus, heterogeneous catalysts are promising candidates for biodiesel production from renewable wastes including used vegetable oils [24]. Thus far, a variety of heterogeneous catalysts such as metal and metal oxides, carbonaceous materials, and metal-organic frameworks (MOFs) based catalysts have been applied successfully and their activity for transesterification has been studied [25-27]. In this regard, MOFs based catalysts have been given significant attention due to their remarkable skeleton structure, which offers immense possibilities of generating diverse basic functionalities [28,29]. MOFs combine the respective beneficial properties of both organic and inorganic components and can incorporate a variety of active sites in their structure, which can be introduced by the proper selection of the constituents involved [30]. Additionally, they offer huge porosity, uniform pore size, controllable functional groups, and structural tenability which are potential characteristics of a catalyst required for the production of biodiesel [31]. Among several MOFs, zirconium-based MOFs have recently gained decent attention in heterogeneous catalysis due to their unique thermal, mechanical and chemical properties [32,33].

Till date, a variety of Zr-based MOFs such as, NU-1000, MOF-808, etc., have been applied for several important catalytic reactions, particularly UiO-66 MOF has gained vast attention [34-37]. The porous crystalline network of UiO-66 typically consists of the imperfect framework with missing linkers leading to the formation of active defects which not only facilitate the adsorption of substrates but also enhance the interactions between reactants [38]. Moreover, the vacant sites on nodes in MOFs with missing linkers, such as in UiO-66, potentially generate Lewis acid sites which further enhance the catalytic properties of Zr-based MOFs [39]. However, there are several other Zr-based MOFs that are not yet explored for their catalytic potential, such as MOF-801. Therefore, in this report, we present the synthesis and catalytic application of fumarate-based MOFs (MOF-801) (Scheme 1), which contains a unique microporous $\mathrm{Zr}$-based 3D structure consisting of $\mathrm{Zr}_{6}$ nodes connected by fumarate linker. 
DMF-Formic acid

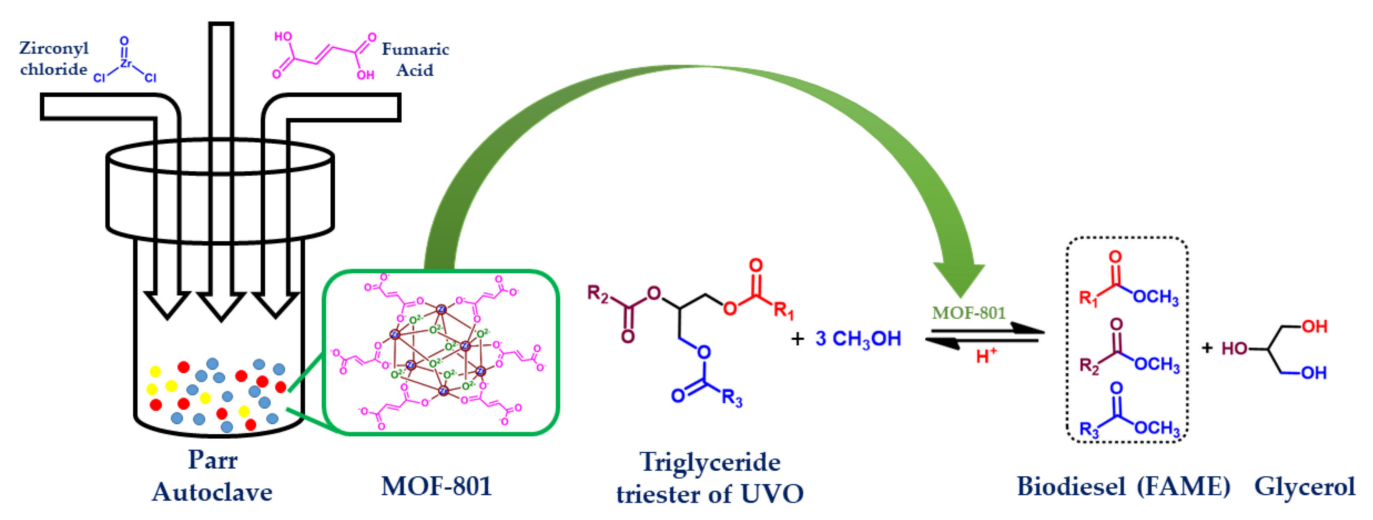

Scheme 1. Graphical representation of $\mathrm{t}$ transesterification of UVO to biodiesel utilizing the synthesized fumarate-based MOFs (MOF-801) catalyst.

\section{Materials and Methods}

\subsection{Preparation of MOF- 801}

In this study, the synthesis of MOF-801 is carried out as per the previously published literature [40]. Briefly, $0.8 \mathrm{~g}$ of $\mathrm{ZrOCl}_{2} \cdot 8 \mathrm{H}_{2} \mathrm{O}$ was dissolved in $15 \mathrm{~mL}$ of DMF-formic acid $(v / v=20: 7)$ mixture in a $50 \mathrm{~mL}$ round bottom flask. To this solution, $0.29 \mathrm{~g}$ of fumaric acid was added and the mixture was left for stirring for $30 \mathrm{~min}$ until a clear solution was obtained. Subsequently, the resultant solution was transferred to a $50 \mathrm{~mL}$ Teflon cup, which was fixed into a hydrothermal/solvothermal autoclave reactor. The reactor was kept in an oven for $6 \mathrm{~h}$ at $130^{\circ} \mathrm{C}$. Thereafter, the product was isolated via centrifugation and washed repeatedly with DMF and ethanol (3 times), and dried overnight under vacuum at $100{ }^{\circ} \mathrm{C}$.

\subsection{Transesterification of Used Vegetables Oil (UVO)}

The UVO for the transesterification was obtained from a fast-food center in Riyadh (KSA). The catalytic reaction was performed in methanol using $3 \mathrm{~g}$ of UVO, $1.5 \mathrm{M}$ of methanol, and $0.3 \mathrm{~g}$ of MOF-801 (10 wt.\% of oil). All the reactants were thoroughly mixed in a $100 \mathrm{~mL}$ beaker via rigorous stirring, and subsequently, the mixture was transferred into a $100 \mathrm{~mL}$ Teflon cup that was fixed into a steel autoclave. The autoclave reactor was heated to $180^{\circ} \mathrm{C}$ in a muffle furnace for $8 \mathrm{~h}$. Thereafter, the reaction was stopped, and the autoclave was allowed to cool down at room temperature. The catalyst was isolated from the mixture via centrifugation at a speed of 8000 RPM. From the resultant reaction mixture, excess methanol was evaporated using a rotary evaporator, which leads to the formation of two separate layers. The upper layers consisted of unreacted oil and transesterification products, while the lower contained glycerol. Using a separating funnel, the lower layer was separated, while the upper layer was processed using a rotary evaporator to collect unreacted oil and transesterification products. The conversion of UVO to esters was confirmed via ${ }^{1} \mathrm{H}$ NMR. All the details about sample preparation for characterization and other technical information about the instruments used during this study is provided in a separate Supplementary Materials file.

\section{Results and Discussions}

\subsection{X-ray Powder Diffraction (XRD) Analysis}

MOF-801 is a three-dimensional, microporous Zr-based MOF consisting of fumarate linkers in which each secondary building unit (SBU) is comprised of six $\mathrm{Zr}$ ions. Every $\mathrm{Zr}$ ion is surrounded by eight oxygen ions, while each SBU is connected with 12 linkers. MOF-801 is considered as a stable MOF due to the presence of strong covalent bonds and excellent coordination between each SBU. SBUs in MOF-801 are slightly tilted due to the presence of non-linear fumarate ions. It contains three different kinds of pores including two types of tetrahedral pores with a diameter of 5.6 and $4.8 \AA$, and octahedral pores with 
7.4 Å diameter [41]. Such types of small pores are convenient for the proper adsorption of small molecules which is very helpful during catalytic reactions. The preparation of MOF-801 and its crystallinity is confirmed by powder X-ray diffraction as shown in Figure 1. The XRD patterns showed well-defined reflection at $\sim 10^{\circ}, 13.9^{\circ}, 19.9^{\circ}$, and $21.7^{\circ}$, which can be assigned to the (200), (222), (420), and (440) planes. These distinct reflections correspond to the most prominent and characteristic diffraction peaks of the simulated crystalline MOF-801 structure reported in a previously published study (Figure S1) [40]. XRD pattern measured for the as-prepared MOF-801 in Figure 1 matched and exhibited a good agreement to the XRD data presented in a previously published study which pointed towards the existence of the cubic (fcu topology) crystalline MOF-801 (Zr-fumarate) [42].

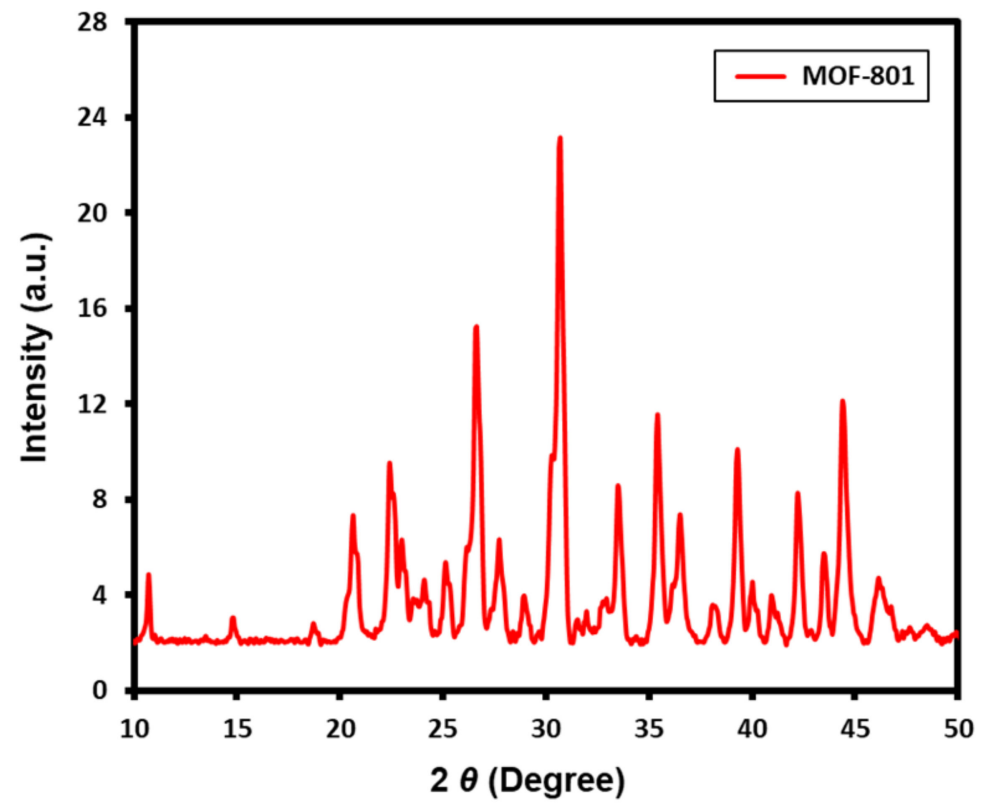

Figure 1. XRD analysis of MOF-801.

\subsection{Fourier-Transform Infrared Spectroscopy (FT-IR) Analysis}

FT-IR is employed to identify the functional groups of MOF-801, and the spectrum is presented in Figure 2. The peaks in the IR spectrum of MOF-801 are identical and matched with previously published data for Zr MOFs [41]. A broad peak at $\sim 3400 \mathrm{~cm}^{-1}$ represents a characteristic peak of the $\mathrm{OH}$ group. The absorption at $1650 \mathrm{~cm}^{-1}$ is attributed to the $\mathrm{C}=\mathrm{O}$ stretching of DMF, and $1578 \mathrm{~cm}^{-1}$ is attributed to the asymmetric stretching of $\mathrm{O}-\mathrm{C}-\mathrm{O}$ belonging to the carboxylic group of ligands, $\mathrm{C}-\mathrm{H}$ symmetrical and asymmetrical stretching appeared in the range of $3100-2800 \mathrm{~cm}^{-1}$, whereas the symmetric stretching of the same group appears at $1403 \mathrm{~cm}^{-1}$. On the other hand, peaks at 1211, 983, and $796 \mathrm{~cm}^{-1}$ can be attributed to $\mathrm{C}-\mathrm{N}$ stretching, $\mathrm{CH}_{3}$ skeletal vibrations, and $\mathrm{C}=\mathrm{C}-\mathrm{H}$ out-of-plane bending. Furthermore, the two sharp peaks at 655 and $491 \mathrm{~cm}^{-1}$ can be assigned to vibrations of $\mathrm{Zr}_{6}(\mathrm{OH})_{4} \mathrm{O}_{4}$ and asymmetric stretching of the $\mathrm{Zr}-(\mathrm{OC})$ group of MOF-801 [43]. 


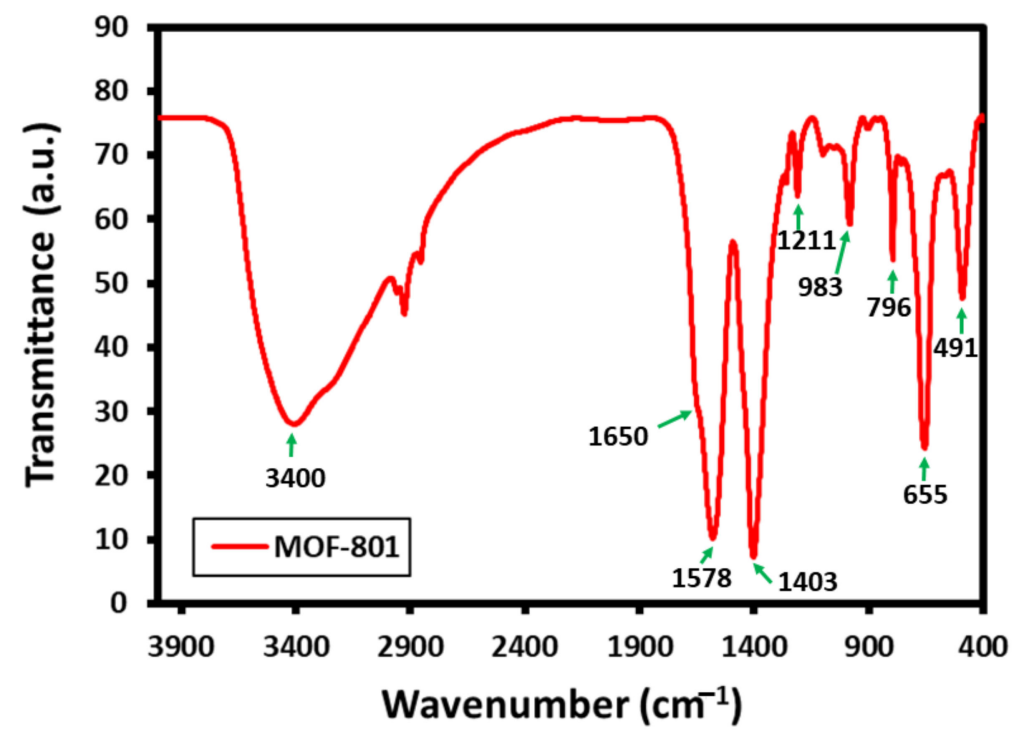

Figure 2. FT-IR analysis of MOF-801.

\subsection{Thermogravimetric Analysis (TGA)}

In order to measure the thermal stability of MOF-801, the sample was subjected to TGA analysis (Figure 3), which revealed weight loss up to $\sim 500{ }^{\circ} \mathrm{C}$ in three steps. The initial weight loss of $\sim 25 \%$ occurred below $125^{\circ} \mathrm{C}$, which is attributed to the removal of moisture from the sample. Subsequently, another 25 to 30\% weight loss between 125 to $350{ }^{\circ} \mathrm{C}$ occurred due to the evaporation of guest molecules, such as solvent molecules from the cavities of the sample. Upon further continuation of heating above $350{ }^{\circ} \mathrm{C}$, the sample started to disintegrate and it was completely decomposed at $\sim 500{ }^{\circ} \mathrm{C}$ due to the breaking of the carboxylate groups network; this indicates the high thermal stability of the sample [44].

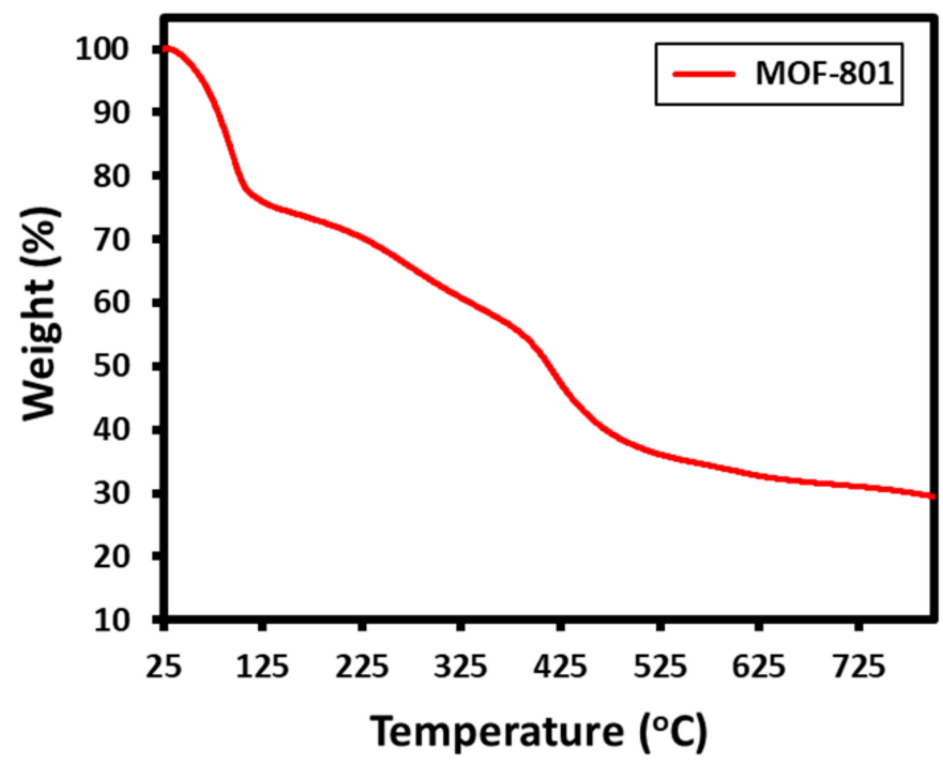

Figure 3. TGA analysis of MOF-801.

\subsection{Scanning Electron Microscopy (SEM), and Energy Dispersive X-ray (EDX) Analysis}

The morphology of the as-prepared MOF-801 was analyzed by SEM, as shown in Figure 4a; dense and defect-free morphology is observed in the micrograph. EDX was further measured to investigate the elemental composition of the sample. Figure $4 \mathrm{~b}$ clearly demonstrates the presence of carbon, oxygen, and zirconium in the sample, which is reflected by the peaks at $\sim 0.28,0.55$, and $2.1 \mathrm{keV}$, respectively. 

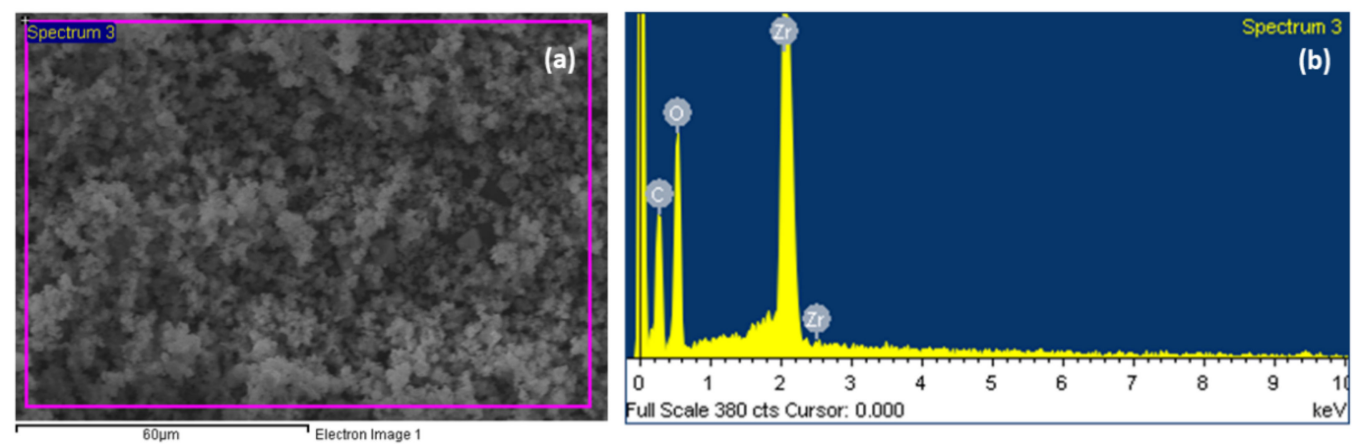

Figure 4. (a) SEM and (b) EDX analysis of MOF-801.

\section{5. $\mathrm{N}_{2}$ Isotherm Analysis}

$\mathrm{N}_{2}$ adsorption-desorption isotherm analyses were performed in order to find out the Brunauer-Emmett-Teller (BET) specific surface area and Barrett-Joyner-Halenda (BJH) pore size distribution of MOF-801. The adsorption-desorption behavior, porosity, and surface area of the as-prepared MOF-801 were examined (cf. Figure 5a) which revealed type-I adsorption behavior, and the calculated BET surface area of $750.11 \mathrm{~m}^{2} / \mathrm{g}$. The pore size distribution curves demonstrate the presence of micropores with large pores distribution of $\sim 20$ to $100 \mathrm{~nm}$ as shown in Figure 5b. These pores are relatively larger than the triglyceride molecules which enable them to trap the substrate and bring it closer to the active sites in the catalytic system.
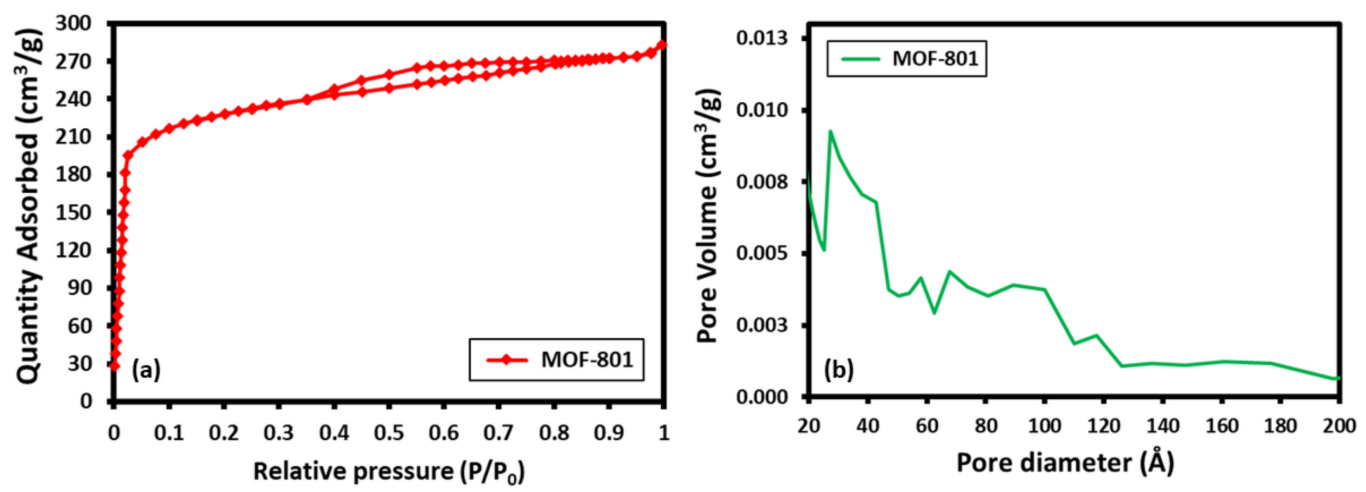

Figure 5. (a) $\mathrm{N}_{2}$ adsorption-desorption isotherm and (b) pore size distribution of MOF-801.

\subsection{Catalytic Evaluation of MOF-801}

MOF-801 was used as a catalyst during the transesterification reaction of UVO. The progress of the reaction was monitored using ${ }^{1} \mathrm{H}$ NMR spectroscopy and was based on the yield of glycerol, which facilitated the estimation of the conversion of UVO. For the sake of simplification, a graphical illustration of the transesterification of triglycerides with $\mathrm{CH}_{3} \mathrm{OH}$ (methanol) is depicted in Figure 6. Typically, the presence of glycerol moieties in triglycerides is ascertained by the appearance of ${ }^{1} \mathrm{H}$ NMR peaks at 4.1 to 4.3 and $5.1 \mathrm{ppm}$, which are associated with the coupling of $-\mathrm{CH}_{2}-$ and $-\mathrm{CH}$ - groups, respectively. Notably, the intensities of the ${ }^{1} \mathrm{H}$ peaks belonging to the triglycerides in the sample collected after reaction (cf. Supplementary Materials Figure S1), decreased significantly which indicated the transformation of the starting materials to the transesterification product. In addition, the ${ }^{1} \mathrm{H}$ spectrum of triglycerides also consists of several other peaks (peaks at 1.30, 1.60, $1.95,2.30$, and $2.63 \mathrm{ppm}$ ) because of the interaction of the $-\mathrm{CH}_{2}-$ group with other moieties. Other ${ }^{1} \mathrm{H}$ peaks in triglycerides and fatty acid methyl esters, which commonly exist due to the conjugated and non-conjugated proton resonances appear at 5.30, 5.35, and $6.03 \mathrm{ppm}$. Apart from triglycerides, mono- and di- glycerides are also present in UVO; however, they do not appear in the ${ }^{1} \mathrm{H}$ spectrum, due to their solubility in $\mathrm{CH}_{3} \mathrm{OH}$ fraction, which is already separated during processing [45]. Apart from all the aforementioned peaks, the ${ }^{1} \mathrm{H}$ 
spectrum of UVO after transesterification also contains a characteristic ${ }^{1} \mathrm{H}$ peak at $3.65 \mathrm{ppm}$, which is associated with the methoxy group of fatty acid methyl ester. This peak is used to calculate the conversion of triglycerides to biodiesel due to the transesterification reaction using the following Equation (1).

$$
\text { Conversion }(\%)=100 \times \frac{2 A_{\mathrm{CH}_{3}}}{3 A_{\alpha-\mathrm{CH}_{2}}}
$$

where $A_{\mathrm{CH}_{3}}=$ area of methoxy protons in the methyl esters, and $A_{\alpha-\mathrm{CH}_{2}}=$ area of the methylene protons adjacent to the carbonyl group.

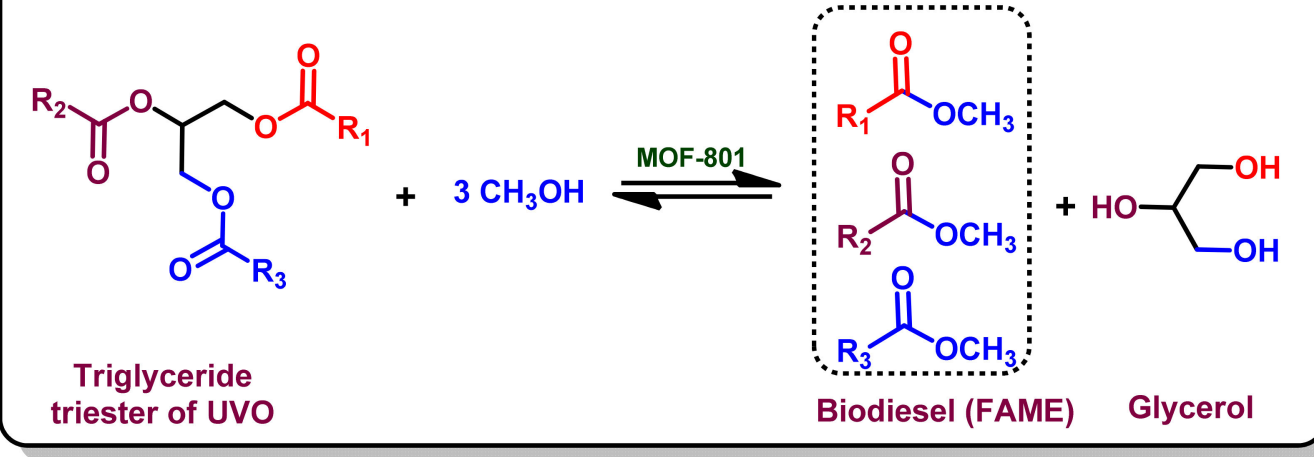

Figure 6. Graphical illustration of the transesterification of triglycerides with methanol.

The transformation of UVO using MOF-801 as catalysts was analyzed by changing the amount of catalyst. The transesterification of UVO was performed in methanol by varying the amount of catalyst between 5 to $20 \mathrm{wt}$.\% of the UVO used during the reaction (Figure 7a). The details of the reaction are given in Table 1. The conversion of the UVO was ascertained by ${ }^{1} \mathrm{H}$ NMR given in Supplementary Materials (Figures S2-S18). MOF-801 (10 wt.\%) rendered $\sim 60 \%$ conversion of UVO in $8 \mathrm{~h}$ of time at a temperature of $180{ }^{\circ} \mathrm{C}$ with a $\mathrm{CH}_{3} \mathrm{OH}$ :oil weight percent of 50. Expectedly, in the absence of catalyst, under similar reaction conditions, the conversion of UVO did not occur. To test the effect of the amount of catalyst of the yield of glycerol, several experiments were performed by changing the amount of catalyst. The result revealed that the amount of catalyst (5-20 wt.\%) had slightly influenced the catalytic properties of the catalyst. For instance, with increasing the amount of catalyst from $5 \%$ to $10 \%$, the yield of the glycerol had increased between $\sim 36 \%$ to $\sim 60 \%$, respectively. However, when the amount of catalyst was further increased from $10 \%$ to $15 \%$ and $20 \%$, the change of the yield of glycerol was negligible, and almost remained the same (cf. Table 1).

Table 1. The transesterification reactions of $\mathrm{UVO}$ in $\mathrm{CH}_{3} \mathrm{OH}$ using different amounts of oil.

\begin{tabular}{|c|c|c|c|c|c|c|c|}
\hline \multirow[b]{2}{*}{ Catalyst } & \multirow[b]{2}{*}{ Oil (g) } & \multicolumn{2}{|c|}{ Amount of Catalyst } & \multicolumn{2}{|c|}{ Product Yield (g) } & \multicolumn{2}{|c|}{ Conversion (\%) } \\
\hline & & wt. \% to Oil & Amount (g) & Biodiesel & Glycerol & ${ }^{1} \mathrm{H}-\mathrm{NMR}$ & $\begin{array}{l}\text { Yield of } \\
\text { Glycerol }\end{array}$ \\
\hline MOF-801 & \multirow{5}{*}{1.5} & 5 & 0.075 & 1.311 & 0.055 & 40.3 & 36.1 \\
\hline MOF-801 & & 10 & 0.150 & 1.406 & 0.091 & 59.8 & 58.7 \\
\hline MOF-801 & & 15 & 0.225 & 1.399 & 0.090 & 59.6 & 58.1 \\
\hline MOF-801 & & 20 & 0.300 & 1.394 & 0.087 & 57.4 & 56.1 \\
\hline MOF-801/HCl & & 10 & 0.150 & 1.482 & 0.107 & 70.0 & 69 \\
\hline
\end{tabular}

Reaction conditions: Temperature- $180{ }^{\circ} \mathrm{C}$, Methanol to oil (50 wt. \%), and time $8 \mathrm{~h}$. 

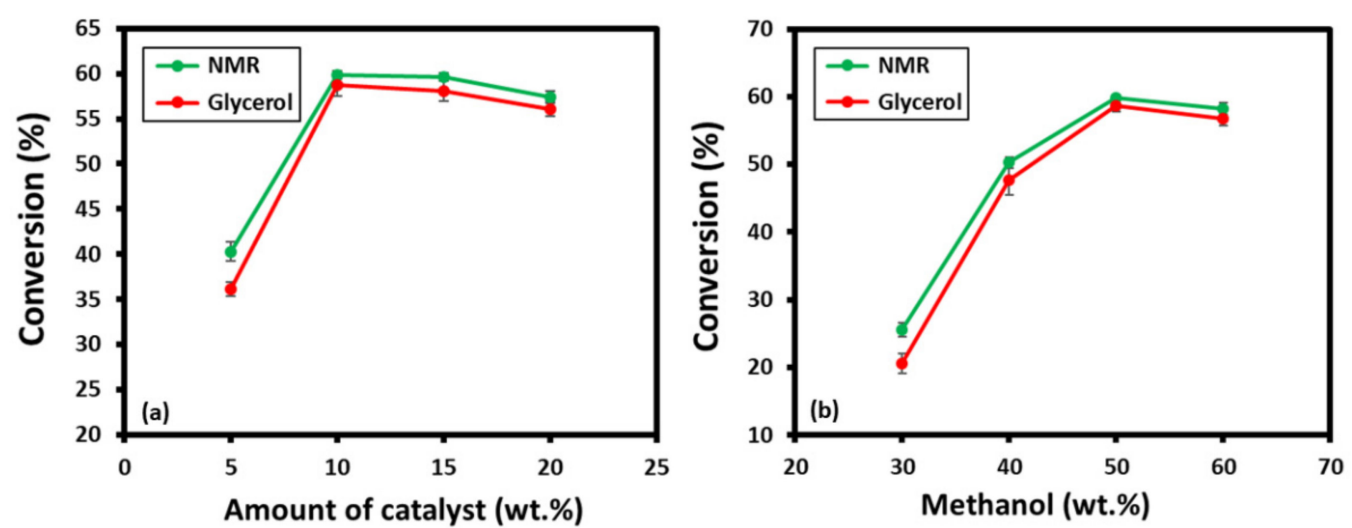

Figure 7. Conversion of UVO in the presence of MOF-801 as catalysts using different reaction parameters (a), at varying catalyst loading. (Green line conversion based on NMR and red line conversion based on the yield of glycerol) and (b) using different amounts of $\mathrm{CH}_{3} \mathrm{OH}$ with respect to oil.

Theoretically, $3 \mathrm{~mol}$ of $\mathrm{CH}_{3} \mathrm{OH}$ is sufficient to produce $1 \mathrm{~mol}$ of triglyceride, but to prevent the reversible reaction, an excess amount of $\mathrm{CH}_{3} \mathrm{OH}$ is used to improve the reaction rate in the forward direction. To investigate the effect of $\mathrm{CH}_{3} \mathrm{OH}$, several experiments were performed by varying the amount of $\mathrm{CH}_{3} \mathrm{OH}$ with respect to oil. For this purpose, the amount of $\mathrm{CH}_{3} \mathrm{OH}$ was used from 30 to 60 weight percent (wt.\%) with respect to reactant (UVO) as shown in Figure $7 \mathrm{~b}$. With increasing the amount of $\mathrm{CH}_{3} \mathrm{OH}$ up to $15 \mathrm{wt}$. \% in the order of 30,40, and $50 \mathrm{wt} \%$ ( $\mathrm{CH}_{3} \mathrm{OH}$ :oil), the conversion was also increased to $\sim 20,48$, and $\sim 60 \%$, respectively. However, when the amount of $\mathrm{CH}_{3} \mathrm{OH}$ was further increased to $60 \mathrm{wt} . \%$, the conversion was decreased to $\sim 56 \%$, which indicated that the optimum amount of $\mathrm{CH}_{3} \mathrm{OH}$ is $50 \mathrm{wt}$ \% of UVO for this reaction. To optimize the time of the reaction, the conversion of UVO was monitored in various reactions by changing the time from 2 to $8 \mathrm{~h}$. Initially, in $2 \mathrm{~h}$ of reaction time only $\sim 35 \%$ of conversion was obtained due to the lower dispersion of oil in $\mathrm{CH}_{3} \mathrm{OH}$. However, as the time of the reaction was increased, the conversion was also increased, and finally at $8 \mathrm{~h}$ of reaction time a maximum of $\sim 60 \%$, which is considered as optimum reaction time (Figure $8 \mathrm{a}$ ). Furthermore, the effect of temperature on the reaction which is known to influence the kinetics of the reaction is also investigated. To do this, different experiments were performed by varying the temperature of the reaction from 140 to $200{ }^{\circ} \mathrm{C}$, while keeping all the other parameters constant. These experiments have revealed an optimum temperature of $180^{\circ} \mathrm{C}$, which has produced the maximum amount of product as shown in Figure $8 \mathrm{~b}$.
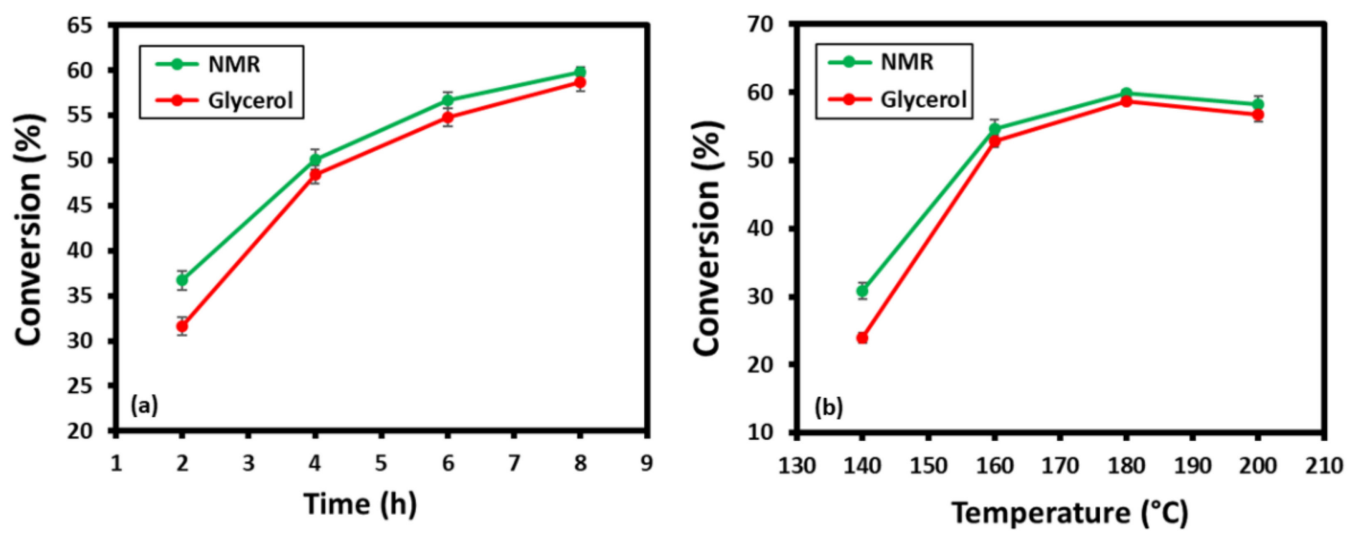

Figure 8. Transesterification of UVO over MOF-801, (a) at a different time interval. (Green line conversion based on NMR and red line conversion based on the yield of glycerol) and (b) at different temperatures. 
Previous reports suggested that the oxygen ions $\left(\mathrm{O}^{2-}\right)$ in catalysts typically promote the reaction in the forward direction and help in enhancing the yield of transesterification products [46]. These oxygen ions are highly negative and tend to function as the Brønsted bases, which could potentially enhance the activity of the catalyst [47]. Typically, in mixed metal oxide based catalysts, the basicity of the catalyst is affected by the electron transfer of the metal groups [48]. Considering this assumption, the positive metal ions ( $\mathrm{Zr}$ (IV) cation) in MOF-801 may facilitate the electron transfer to the oxygen anions $\left(\mathrm{O}^{2-}\right)$ leading to an enhanced electron density at the sites [49]. These highly negative sites become susceptible to nucleophilic attack, and thus function as Brønsted bases. These basic sites tend to adsorb $\mathrm{CH}_{3} \mathrm{OH}$ (methanol) molecules leading to the formation of $\mathrm{CH}_{3} \mathrm{O}^{-}$(methoxide anions) and $\mathrm{H}^{+}$(hydrogen cations). During the reaction, the former reacts $\left(\mathrm{CH}_{3} \mathrm{O}^{-}\right)$with triglycerides to produce biodiesel. To ascertain this, the $\mathrm{pH}$ of the reaction is slightly changed by adding a little amount of $\mathrm{HCl}(10 \% v / v)$. Surprisingly, the conversion of the reactant (UVO) is further enhanced to $\sim 70 \%$. This could be attributed to the inherent catalytic activity of $\mathrm{HCl}$, which effectively acts as a catalyst during homogeneous transesterification reactions to produce biodiesel [50]. Finally, the reusability of catalyst was also investigated under optimized reaction conditions, i.e., $10 \mathrm{wt} . \%$ of catalyst and $50 \mathrm{wt} . \%$ of UFO with respect to oil, while the reactions were performed for $8 \mathrm{~h}$ at $180^{\circ} \mathrm{C}$ temperature. Over these reactions, up to three cycles, the efficiency of catalyst has slightly reduced, and at the end of the 3rd cycle the yield of the product has decreased up to $\sim 10 \%$, as shown in Figure 9 in $8 \mathrm{~h}$ of time.

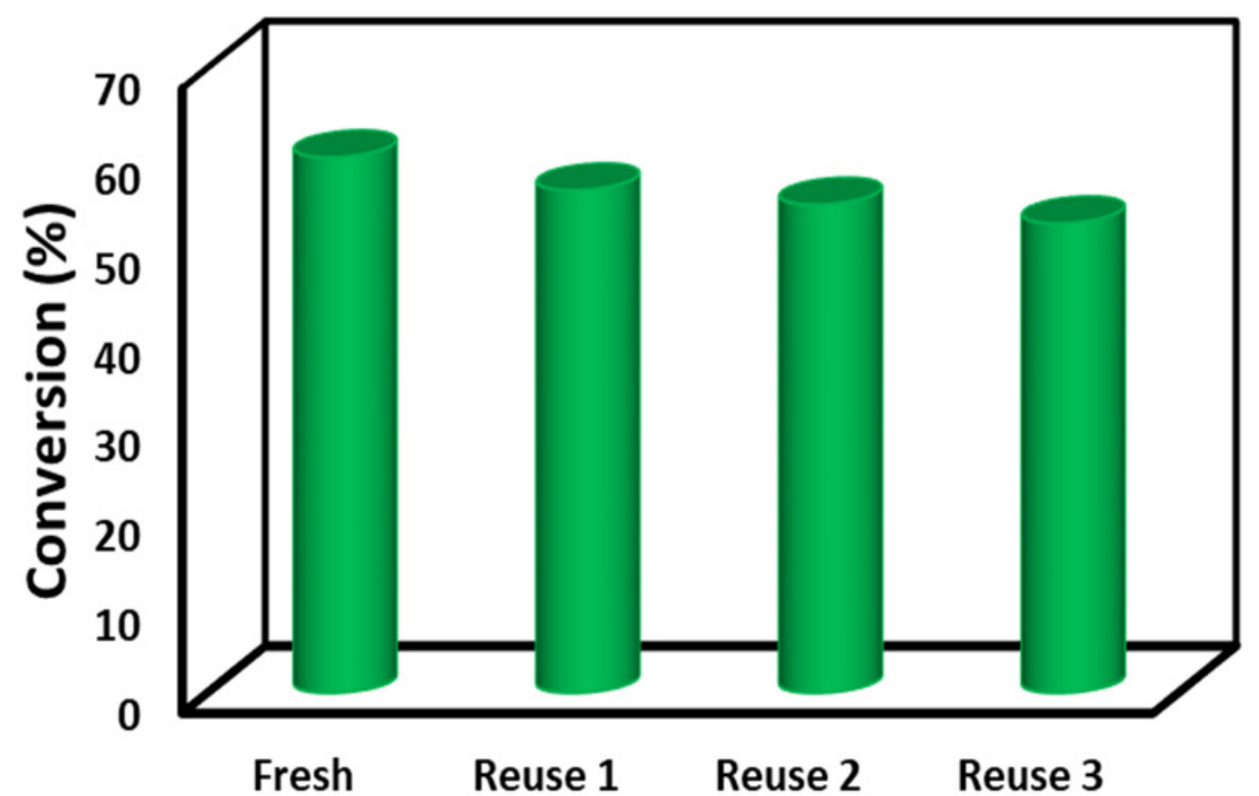

Figure 9. Reusability study of the MOF-801catalyst for the transesterification of UVO.

\section{Conclusions}

Herein, we have successfully demonstrated the preparation of MOF-801 catalyst under solvothermal conditions at an optimum temperature of $130^{\circ} \mathrm{C}$. Detailed characterization of catalysts was performed to recognize the formation and stability of the as-prepared catalyst. $\mathrm{XRD}$ analysis has indicated the formation of crystalline and cubic Zr-fumarate based MOF801. SEM and EDX have confirmed the elemental identity of the sample, while TGA exhibited the thermal stability until $500^{\circ} \mathrm{C}$, which is sufficient for the biodiesel production processes. The as-prepared sample (MOF-801) is applied for the transesterification of UVO for the production of biodiesel, which has demonstrated moderate catalytic activity under facile conditions. The activity of the catalyst may be attributed to the catalytically active ionic sites in the crystal structure including cationic $\mathrm{Zr}$ and anionic $\mathrm{O}_{2}$ sites. These results can be further used towards the application of MOFs as heterogeneous catalysts in biodiesel production from UVO on a larger scale. 
Supplementary Materials: The following supporting information can be downloaded at: https: / / www.mdpi.com/article/10.3390/cryst12020151/s1. Figure S1: (a) Comparison of the simulated MOF-801 from the previously published data [1] and (b) as-synthesized XRD patterns of MOF-801; Figure S2: 1H-NMR spectrum of used vegetable oil (UVO); Figure S3: 1H-NMR spectrum of biodiesel synthesized by transesterification of UVO using MOF- 801 catalyst ( $5 \mathrm{wt} . \%$ to oil) at $180{ }^{\circ} \mathrm{C}$ in $8 \mathrm{~h}$ with methanol to oil $50 \mathrm{wt}$ \%; Figure S4: 1H-NMR spectrum of biodiesel synthesized by transesterification of UVO using MOF-801 catalyst (10 wt.\% to oil) at $180{ }^{\circ} \mathrm{C}$ in $8 \mathrm{~h}$ with methanol to oil $50 \mathrm{wt} . \%$; Figure S5: 1H-NMR spectrum of biodiesel synthesized by transesterification of UVO using MOF-801 catalyst ( $15 \mathrm{wt} . \%$ to oil) at $180{ }^{\circ} \mathrm{C}$ in $8 \mathrm{~h}$ with methanol to oil $50 \mathrm{wt} . \%$; Figure S6: $1 \mathrm{H}-\mathrm{NMR}$ spectrum of biodiesel synthesized by transesterification of UVO using MOF-801 catalyst (20 wt.\% to oil) at $180{ }^{\circ} \mathrm{C}$ in $8 \mathrm{~h}$ with methanol to oil $50 \mathrm{wt} . \%$; Figure S7: 1H-NMR spectrum of biodiesel synthesized by transesterification of UVO using MOF- 801 catalyst (10 wt. \% to oil) at $180{ }^{\circ} \mathrm{C}$ in $8 \mathrm{~h}$ with methanol to oil $30 \mathrm{wt} . \%$; Figure S8: 1H-NMR spectrum of biodiesel synthesized by transesterification of UVO using MOF-801 catalyst (10 wt.\% to oil) at $180{ }^{\circ} \mathrm{C}$ in $8 \mathrm{~h}$ with methanol to oil $40 \mathrm{wt} . \%$; Figure S9: $1 \mathrm{H}-\mathrm{NMR}$ spectrum of biodiesel synthesized by transesterification of UVO using MOF-801 catalyst (10 wt.\% to oil) at $180{ }^{\circ} \mathrm{C}$ in $8 \mathrm{~h}$ with methanol to oil $50 \mathrm{wt} . \%$; Figure S10: $1 \mathrm{H}-\mathrm{NMR}$ spectrum of biodiesel synthesized by transesterification of UVO using MOF-801 catalyst (10 wt.\% to oil) at $180{ }^{\circ} \mathrm{C}$ in $8 \mathrm{~h}$ with methanol to oil $60 \mathrm{wt} . \%$; Figure S11: 1H-NMR spectrum of biodiesel synthesized by transesterification of UVO using MOF-801 catalyst (10 wt. \% to oil) at $180{ }^{\circ} \mathrm{C}$ in $2 \mathrm{~h}$ with methanol to oil $50 \mathrm{wt}$ \%; Figure S12: 1H-NMR spectrum of biodiesel synthesized by transesterification of UVO using MOF-801 catalyst (10 wt.\% to oil) at $180{ }^{\circ} \mathrm{C}$ in $4 \mathrm{~h}$ with methanol to oil $50 \mathrm{wt} . \%$; Figure S13: $1 \mathrm{H}-\mathrm{NMR}$ spectrum of biodiesel synthesized by transesterification of UVO using MOF-801 catalyst (10 wt.\% to oil) at $180{ }^{\circ} \mathrm{C}$ in $6 \mathrm{~h}$ with methanol to oil $50 \mathrm{wt}$ \%\%; Figure S14: 1H-NMR spectrum of biodiesel synthesized by transesterification of UVO using MOF- 801 catalyst (10 wt.\% to oil) at $180{ }^{\circ} \mathrm{C}$ in $8 \mathrm{~h}$ with methanol to oil $50 \mathrm{wt} . \%$; Figure S15: 1H-NMR spectrum of biodiesel synthesized by transesterification of UVO using MOF-801 catalyst (10 wt. \% to oil) at $140{ }^{\circ} \mathrm{C}$ in $8 \mathrm{~h}$ with methanol to oil 50 wt.\%; Figure S16: 1H-NMR spectrum of biodiesel synthesized by transesterification of UVO using MOF-801 catalyst (10 wt.\% to oil) at $160{ }^{\circ} \mathrm{C}$ in $8 \mathrm{~h}$ with methanol to oil $50 \mathrm{wt}$ \%; Figure S17: 1H-NMR spectrum of biodiesel synthesized by transesterification of UVO using MOF-801 catalyst (10 wt.\% to oil) at $180{ }^{\circ} \mathrm{C}$ in $8 \mathrm{~h}$ with methanol to oil $50 \mathrm{wt} . \%$; Figure S18: $1 \mathrm{H}-\mathrm{NMR}$ spectrum of biodiesel synthesized by transesterification of UVO using MOF- 801 catalyst (10 wt. $\%$ to oil) at $200{ }^{\circ} \mathrm{C}$ in $8 \mathrm{~h}$ with methanol to oil $50 \mathrm{wt} . \%$.

Author Contributions: M.R.S.: Investigation, Formal analysis, writing-original draft; S.F.A.: Investigation, Validation, Methodology, Writing-review \& editing; Z.A.A.: Visualization, Resources, Supervision; O.M.A.: Conceptualization, Resources, Supervision, Writing-review \& editing, Funding acquisition. All authors have read and agreed to the published version of the manuscript.

Funding: The authors extend their appreciation to the Deputyship for Research\& Innovation, Ministry of Education in Saudi Arabia for funding this research work through the project number (DRI-KSU-572).

Institutional Review Board Statement: Not applicable.

Informed Consent Statement: Not applicable.

Data Availability Statement: Not applicable.

Acknowledgments: The authors extend their appreciation to the Deputyship for Research\& Innovation, Ministry of Education in Saudi Arabia for funding this research work through the project number (DRI-KSU-572).

Conflicts of Interest: The authors declare no conflict of interest.

\section{References}

1. Fernández-Dacosta, C.; Shen, L.; Schakel, W.; Ramirez, A.; Kramer, G.J. Potential and challenges of low-carbon energy options: Comparative assessment of alternative fuels for the transport sector. Appl. Energy 2019, 236, 590-606. [CrossRef]

2. Abdulkareem-Alsultan, G.; Asikin-Mijan, N.; Lee, H.; Taufiq-Yap, Y. Biofuels: Past, Present, Future. In Innovations in Sustainable Energy and Cleaner Environment; Springer: Berlin/Heidelberg, Germany, 2020; pp. 489-504.

3. Nguyen, D.C. Development of biofuels for a green future. Eur. J. Eng. Technol. Res. 2019, 4, 115-120. 
4. Liu, H.; Huang, Y.; Yuan, H.; Yin, X.; Wu, C. Life cycle assessment of biofuels in China: Status and challenges. Renew. Sustain. Energy Rev. 2018, 97, 301-322. [CrossRef]

5. Chuah, L.F.; Klemeš, J.J.; Yusup, S.; Bokhari, A.; Akbar, M.M. A review of cleaner intensification technologies in biodiesel production. J. Clean. Prod. 2017, 146, 181-193. [CrossRef]

6. Okoye, P.; Hameed, B. Review on recent progress in catalytic carboxylation and acetylation of glycerol as a byproduct of biodiesel production. Renew. Sustain. Energy Rev. 2016, 53, 558-574. [CrossRef]

7. Baskar, G.; Aiswarya, R. Trends in catalytic production of biodiesel from various feedstocks. Renew. Sustain. Energy Rev. 2016, 57, 496-504. [CrossRef]

8. Janaun, J.; Ellis, N. Perspectives on biodiesel as a sustainable fuel. Renew. Sustain. Energy Rev. 2010, 14, 1312-1320. [CrossRef]

9. Shan, R.; Lu, L.; Shi, Y.; Yuan, H.; Shi, J. Catalysts from renewable resources for biodiesel production. Energy Convers. Manag. 2018, 178, 277-289. [CrossRef]

10. Vicente, G.; Martınez, M.; Aracil, J. Integrated biodiesel production: A comparison of different homogeneous catalysts systems. Bioresour. Technol. 2004, 92, 297-305. [CrossRef] [PubMed]

11. Benessere, V.; Cucciolito, M.E.; Esposito, R.; Lega, M.; Turco, R.; Ruffo, F.; Di Serio, M. A novel and robust homogeneous supported catalyst for biodiesel production. Fuel 2016, 171, 1-4. [CrossRef]

12. Tiwari, A.K.; Kumar, A.; Raheman, H. Biodiesel production from jatropha oil (Jatropha curcas) with high free fatty acids: An optimized process. Biomass Bioenergy 2007, 31, 569-575. [CrossRef]

13. Macario, A.; Giordano, G.; Onida, B.; Cocina, D.; Tagarelli, A.; Giuffrè, A.M. Biodiesel production process by homogeneous/heterogeneous catalytic system using an acid-base catalyst. Appl. Catal. A Gen. 2010, 378, 160-168. [CrossRef]

14. De Lima, A.L.; Ronconi, C.M.; Mota, C.J. Heterogeneous basic catalysts for biodiesel production. Catal. Sci. Technol. 2016, 6 , 2877-2891. [CrossRef]

15. Alsalme, A.; Alsharif, A.A.; Al-Enizi, H.; Khan, M.; Alshammari, S.G.; Alotaibi, M.A.; Khan, R.A.; Siddiqui, M.R.H. Probing the catalytic efficiency of supported heteropoly acids for esterification: Effect of weak catalyst support interactions. J. Chem. 2018, 2018, 7037461. [CrossRef]

16. Marwaha, A.; Dhir, A.; Mahla, S.K.; Mohapatra, S.K. An overview of solid base heterogeneous catalysts for biodiesel production. Catal. Rev. 2018, 60, 594-628. [CrossRef]

17. Meira, M.; Quintella, C.; Ribeiro, E.; Silva, H.; Guimarães, A. Overview of the challenges in the production of biodiesel. Biomass Convers. Biorefinery 2015, 5, 321-329. [CrossRef]

18. Abbaszaadeh, A.; Ghobadian, B.; Omidkhah, M.R.; Najafi, G. Current biodiesel production technologies: A comparative review. Energy Convers. Manag. 2012, 63, 138-148. [CrossRef]

19. Hayyan, A.; Alam, M.Z.; Mirghani, M.E.; Kabbashi, N.A.; Hakimi, N.I.N.M.; Siran, Y.M.; Tahiruddin, S. Reduction of high content of free fatty acid in sludge palm oil via acid catalyst for biodiesel production. Fuel Process. Technol. 2011, 92, 920-924. [CrossRef]

20. Gui, M.M.; Lee, K.; Bhatia, S. Feasibility of edible oil vs. non-edible oil vs. waste edible oil as biodiesel feedstock. Energy 2008, 33, 1646-1653. [CrossRef]

21. Gebremariam, S.; Marchetti, J. Economics of biodiesel production. Energy Convers. Manag. 2018, 168, 74-84. [CrossRef]

22. Borges, M.E.; Díaz, L. Recent developments on heterogeneous catalysts for biodiesel production by oil esterification and transesterification reactions: A review. Renew. Sustain. Energy Rev. 2012, 16, 2839-2849. [CrossRef]

23. Olkiewicz, M.; Plechkova, N.V.; Earle, M.J.; Fabregat, A.; Stüber, F.; Fortuny, A.; Font, J.; Bengoa, C. Biodiesel production from sewage sludge lipids catalysed by Brønsted acidic ionic liquids. Appl. Catal. B Environ. 2016, 181, 738-746. [CrossRef]

24. Adekunle, A.S.; Oyekunle, J.A.O.; Oduwale, A.I.; Owootomo, Y.; Obisesan, O.R.; Elugoke, S.E.; Durodola, S.S.; Akintunde, S.B.; Oluwafemi, O.S. Biodiesel potential of used vegetable oils transesterified with biological catalysts. Energy Rep. 2020, 6, $2861-2871$. [CrossRef]

25. Kuniyil, M.; Kumar, J.S.; Adil, S.F.; Assal, M.E.; Shaik, M.R.; Khan, M.; Al-Warthan, A.; Siddiqui, M.R.H. Production of biodiesel from waste cooking oil using $\mathrm{ZnCuO} / \mathrm{N}$-doped graphene nanocomposite as an efficient heterogeneous catalyst. Arab. J. Chem. 2021, 14, 102982. [CrossRef]

26. Bilal, M.; Qamar, S.A.; Yadav, V.; Cheng, H.; Khan, M.; Adil, S.F.; Taherzadeh, M.J.; Iqbal, H.M. Exploring the potential of ligninolytic armory for lignin valorization-A way forward for sustainable and cleaner production. J. Clean. Prod. 2021, 326, 129420. [CrossRef]

27. Clohessy, J.; Kwapinski, W. Carbon-based catalysts for biodiesel production-A review. Appl. Sci. 2020, 10, 918. [CrossRef]

28. Zhu, L.; Liu, X.-Q.; Jiang, H.-L.; Sun, L.-B. Metal-organic frameworks for heterogeneous basic catalysis. Chem. Rev. 2017, 117, 8129-8176. [CrossRef]

29. Cong, W.-J.; Nanda, S.; Li, H.; Fang, Z.; Dalai, A.K.; Kozinski, J.A. Metal-organic framework-based functional catalytic materials for biodiesel production: A review. Green Chem. 2021, 23, 2595-2618. [CrossRef]

30. Ma, X.; Liu, F.; Helian, Y.; Li, C.; Wu, Z.; Li, H.; Chu, H.; Wang, Y.; Wang, Y.; Lu, W. Current application of MOFs based heterogeneous catalysts in catalyzing transesterification/esterification for biodiesel production: A review. Energy Convers. Manag. 2021, 229, 113760. [CrossRef]

31. Zhang, Q.; Zhang, Y.; Cheng, J.; Li, H.; Ma, P. An Overview of Metal-organic Frameworks-based Acid/Base Catalysts for Biofuel Synthesis. Curr. Org. Chem. 2020, 24, 1876-1891. [CrossRef] 
32. Trickett, C.A.; Popp, T.M.O.; Su, J.; Yan, C.; Weisberg, J.; Huq, A.; Urban, P.; Jiang, J.; Kalmutzki, M.J.; Liu, Q. Identification of the strong Brønsted acid site in a metal-organic framework solid acid catalyst. Nat. Chem. 2019, 11, 170-176. [CrossRef]

33. Lu, Z.; Liu, J.; Zhang, X.; Liao, Y.; Wang, R.; Zhang, K.; Lyu, J.; Farha, O.K.; Hupp, J.T. Node-Accessible Zirconium MOFs. J. Am. Chem. Soc. 2020, 142, 21110-21121. [CrossRef]

34. Deria, P.; Gómez-Gualdrón, D.A.; Hod, I.; Snurr, R.Q.; Hupp, J.T.; Farha, O.K. Framework-topology-dependent catalytic activity of zirconium-based (porphinato) zinc (II) MOFs. J. Am. Chem. Soc. 2016, 138, 14449-14457. [CrossRef] [PubMed]

35. Ahn, S.; Nauert, S.L.; Buru, C.T.; Rimoldi, M.; Choi, H.; Schweitzer, N.M.; Hupp, J.T.; Farha, O.K.; Notestein, J.M. Pushing the limits on metal-organic frameworks as a catalyst support: NU-1000 supported tungsten catalysts for o-xylene isomerization and disproportionation. J. Am. Chem. Soc. 2018, 140, 8535-8543. [CrossRef] [PubMed]

36. Mautschke, H.-H.; Drache, F.; Senkovska, I.; Kaskel, S.; i Xamena, F.L. Catalytic properties of pristine and defect-engineered Zr-MOF-808 metal organic frameworks. Catal. Sci. Technol. 2018, 8, 3610-3616. [CrossRef]

37. Cirujano, F.; Llabrés i Xamena, F.X. Tuning the Catalytic Properties of UiO-66 Metal-Organic Frameworks: From Lewis to Defect-Induced Brønsted Acidity. J. Phys. Chem. Lett. 2020, 11, 4879-4890. [CrossRef]

38. Feng, Y.; Chen, Q.; Jiang, M.; Yao, J. Tailoring the properties of UiO-66 through defect engineering: A review. Ind. Eng. Chem. Res. 2019, 58, 17646-17659. [CrossRef]

39. Dhakshinamoorthy, A.; Santiago-Portillo, A.; Asiri, A.M.; García Gómez, H. Engineering UiO-66 Metal Organic Framezork for Heterogeneous Catalysis; John Wiley \& Sons: Hoboken, NJ, USA, 2019.

40. Ke, F.; Peng, C.; Zhang, T.; Zhang, M.; Zhou, C.; Cai, H.; Zhu, J.; Wan, X. Fumarate-based metal-organic frameworks as a new platform for highly selective removal of fluoride from brick tea. Sci. Rep. 2018, 8, 939. [CrossRef]

41. Butova, V.V.; Pankin, I.A.; Burachevskaya, O.A.; Vetlitsyna-Novikova, K.S.; Soldatov, A.V. New fast synthesis of MOF-801 for water and hydrogen storage: Modulator effect and recycling options. Inorg. Chim. Acta 2021, 514, 120025. [CrossRef]

42. Diab, K.E.; Salama, E.; Hassan, H.S.; Abd El-moneim, A.; Elkady, M.F. Biocompatible MIP-202 Zr-MOF tunable sorbent for cost-effective decontamination of anionic and cationic pollutants from waste solutions. Sci. Rep. 2021, 11, 6619. [CrossRef]

43. Butova, V.V.; Burachevskaya, O.A.; Ozhogin, I.V.; Borodkin, G.S.; Starikov, A.G.; Bordiga, S.; Damin, A.; Lillerud, K.P.; Soldatov, A.V. UiO-66 type MOFs with mixed-linkers-1,4-Benzenedicarboxylate and 1,4-naphthalenedicarboxylate: Effect of the modulator and post-synthetic exchange. Microporous Mesoporous Mater. 2020, 305, 110324. [CrossRef]

44. Sun, J.; Li, Q.; Chen, G.; Duan, J.; Liu, G.; Jin, W. MOF-801 incorporated PEBA mixed-matrix composite membranes for CO2 capture. Sep. Purif. Technol. 2019, 217, 229-239. [CrossRef]

45. Di Pietro, M.E.; Mannu, A.; Mele, A. NMR Determination of Free Fatty Acids in Vegetable Oils. Processes 2020, 8, 410. [CrossRef]

46. Rao, A.V.R.K.; Dudhe, P.; Chelvam, V. Role of oxygen defects in basicity of Se doped ZnO nanocatalyst for enhanced triglyceride transesterification in biodiesel production. Catal. Commun. 2021, 149, 106258. [CrossRef]

47. Ibrahim, M.L.; Nik Abdul Khalil, N.N.A.; Islam, A.; Rashid, U.; Ibrahim, S.F.; Sinar Mashuri, S.I.; Taufiq-Yap, Y.H. Preparation of $\mathrm{Na}_{2} \mathrm{O}$ supported CNTs nanocatalyst for efficient biodiesel production from waste-oil. Energy Convers. Manag. 2020, 205, 112445. [CrossRef]

48. Lee, D.U.; Xu, P.; Cano, Z.P.; Kashkooli, A.G.; Park, M.G.; Chen, Z. Recent progress and perspectives on bi-functional oxygen electrocatalysts for advanced rechargeable metal-air batteries. J. Mater. Chem. A 2016, 4, 7107-7134. [CrossRef]

49. Jahan, I.; Rupam, T.H.; Palash, M.L.; Rocky, K.A.; Saha, B.B. Energy efficient green synthesized MOF-801 for adsorption cooling applications. J. Mol. Liq. 2022, 345, 117760. [CrossRef]

50. Kim, Z.H.; Park, H.; Ryu, Y.-J.; Shin, D.-W.; Hong, S.-J.; Tran, H.-L.; Lim, S.-M.; Lee, C.-G. Algal biomass and biodiesel production by utilizing the nutrients dissolved in seawater using semi-permeable membrane photobioreactors. J. Appl. Phycol. 2015, 27, 1763-1773. [CrossRef] 